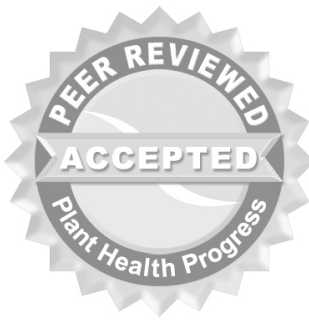

(c) 2009 Plant Management Network.

Accepted for publication 15 March 2009. Published 13 May 2009.

\title{
A Standard Greenhouse Method for Assessing Soybean Cyst Nematode Resistance in Soybean: SCE08 (Standardized Cyst Evaluation 2008)
}

T. L. Niblack, Professor, Department of Crop Sciences, University of Illinois, Urbana, IL 61801; Gregory L. Tylka, Professor, Department of Plant Pathology, I owa State University, Ames, IA 50011;

Prakash Arelli, Supervisory Research Geneticist, USDA-ARS, Jackson, TN 38301; J ason Bond, Associate Professor, Department of Plant, Soil, and Agricultural Systems, Southern Illinois University, Carbondale, IL 62901; Brian Diers, Professor, Department of Crop Sciences, University of Illinois, Urbana, IL 61801; Pat Donald, Research Plant Pathologist, USDA-ARS, Jackson, TN 38301; J amal Faghihi, Research and Extension Nematologist, and V. R. Ferris, Professor, Department of Entomology, Purdue University, West Lafayette, IN 47907; Karen Gallo, Soybean Breeder, Syngenta Seeds Inc., Bay, AR 72411; Robert D. Heinz, Research Specialist, Division of Plant Sciences, University of Missouri, Columbia, MO 65211; Horacio Lopez-Nicora, Graduate Research Assistant, Department of Crop Sciences, University of Illinois, Urbana, IL 61801; Ralph Von Qualen, Chief Executive Officer, Agricultural Consulting and Testing Services Inc., Carroll, IA 51401;

Tom Welacky, Research Biologist, Agriculture Canada, Harrow, Ontario NOR 1G0; and John Wilcox, Research Associate, Division of Plant Sciences, University of Missouri, Columbia, MO 65211

Corresponding author: T. L. Niblack. tniblack@illinois.edu

Niblack, T., Tylka, G. L., Arelli, P., Bond, J., Diers, B., Donald, P., Faghihi, J., Ferris, V. R., Gallo, K., Heinz, R. D., Lopez-Nicora, H., Von Qualen, R., Welacky, T., and Wilcox, J. 2009. A standard greenhouse method for assessing soybean cyst nematode resistance in soybean: SCE08 (standardized cyst evaluation 2008). Online. Plant Health Progress doi: 10.1094/PHP-2009-0513-01-RV.

\section{I ntroduction}

The soybean cyst nematode (SCN), Heterodera glycines Ichinohe, is distributed throughout the soybean [Glycine max (L.) Merr.] production areas of the United States and Canada (Fig. 1) (26). SCN remains the most economically important pathogen of soybean in North America; the most recent estimate of soybean yield reduction in North America due to SCN totaled 34,659,000 metric tons during 2006 (34). 


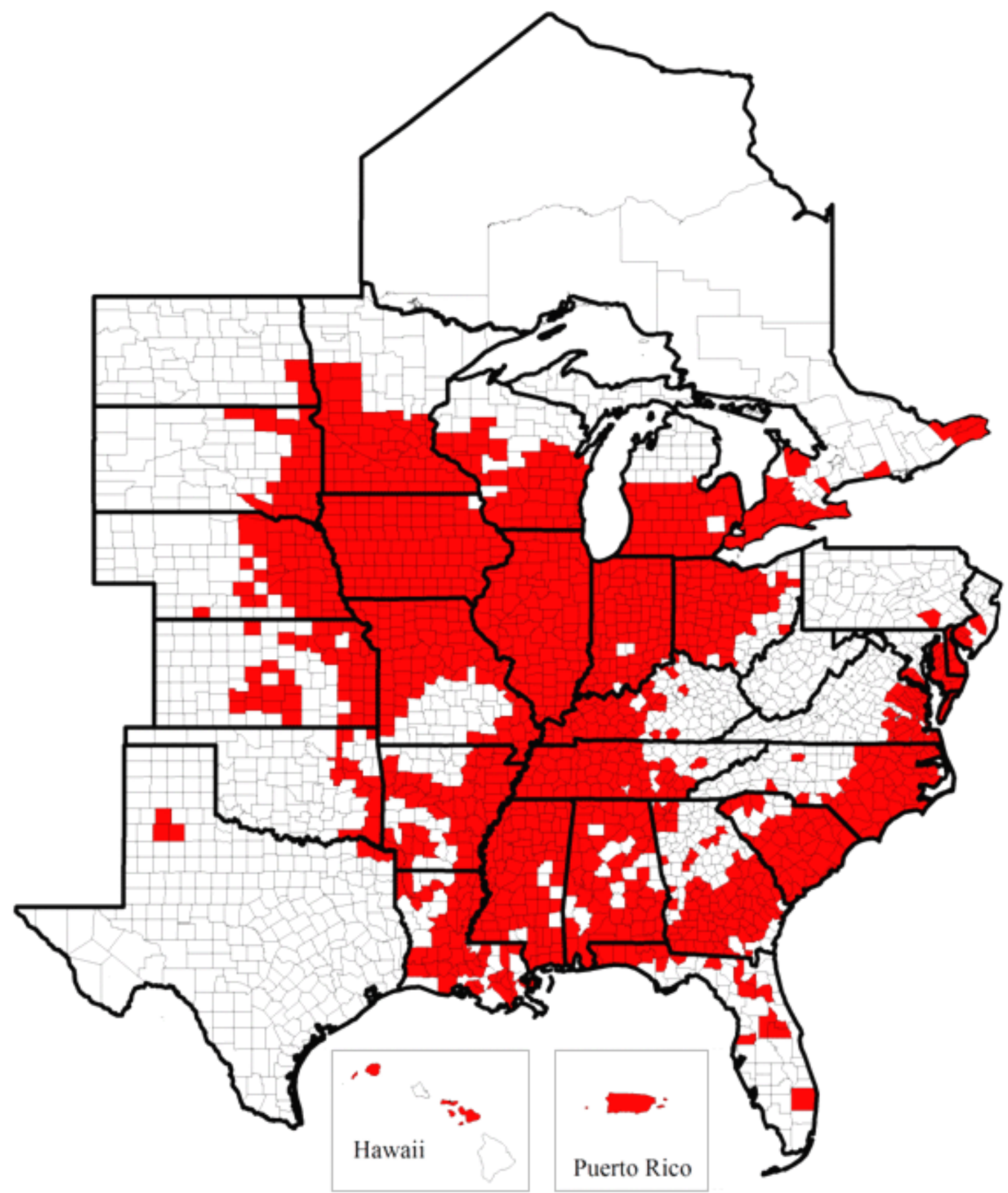

Fig. 1. Distribution of the soybean cyst nematode in North America in 2008. (Data provided by R. D. Riggs and G. L. Tylka).

Overwhelmingly, the tactic of choice for managing soybean in SCN-infested fields is the use of resistant cultivars. In Illinois, for example, where more than $80 \%$ of the soybean fields are known to be infested with SCN $(25,33), 62 \%$ of farmers surveyed in 2007 reported that more than $75 \%$ of the soybean seed they planted was labeled resistant to SCN; an additional 32\% of farmers reported that they also planted resistant cultivars, but on a lower percentage of their fields ( $T$. Niblack, unpublished data). Unfortunately, only $22 \%$ of the same farmers reported that they routinely sampled their infested fields for SCN. Two inferences from these results are: (i) most farmers in Illinois are aware that they have, or could have, SCN infestations; and (ii) most Illinois farmers believe that simply using a soybean cultivar labeled "SCN-resistant" is sufficient to manage the problem without needing to collect soil samples from fields to monitor SCN population densities and be sure that nematode numbers are not increasing. 
Soybean growers in other states likely share these views (10). There are two main difficulties with growing SCN-resistant soybean varieties continuously and not monitoring SCN populations: first, SCN populations vary widely in densities (numbers) and virulence (ability to reproduce on resistant cultivars), and both of these SCN population characteristics influence soybean yield; and second, that the word "resistant" on the seed label does not necessarily mean that the cultivar is actually resistant.

Assessment of hundreds of cultivars over many years in Illinois, Iowa, Missouri, and other states has shown that soybean cultivars labeled "resistant to race 3 " have a wide range of reactions to field and greenhouse SCN populations identified as race 3 [e.g., $(1,14,18,21,22,31)]$. For example, greenhouse assessment of the "resistant" entries in the Illinois Soybean Variety Trials showed that $72 \%$ did not qualify as "resistant" by the traditional definition, i.e., a Female Index (FI) less than 10 (Fig. 2) (29). The disconnect between soybean cultivar SCN resistance labeling and verification of ability to suppress reproduction of the nematode is due to three main factors: (i) resistance to SCN in soybean is quantitative, not "+" or "- "; (ii) the amount of SCN reproduction that occurs on a soybean cultivar is determined by the virulence genes and their frequency in the SCN population as well as the resistance genes present in the soybean cultivar; and (iii) there are currently no widely accepted standards for verifying and labeling a soybean cultivar "SCN resistant." Stated another way: there is no legal definition of resistance to SCN for soybean cultivars in the United States. The purpose of this paper is to propose standards for labeling soybean cultivars as resistant to SCN.

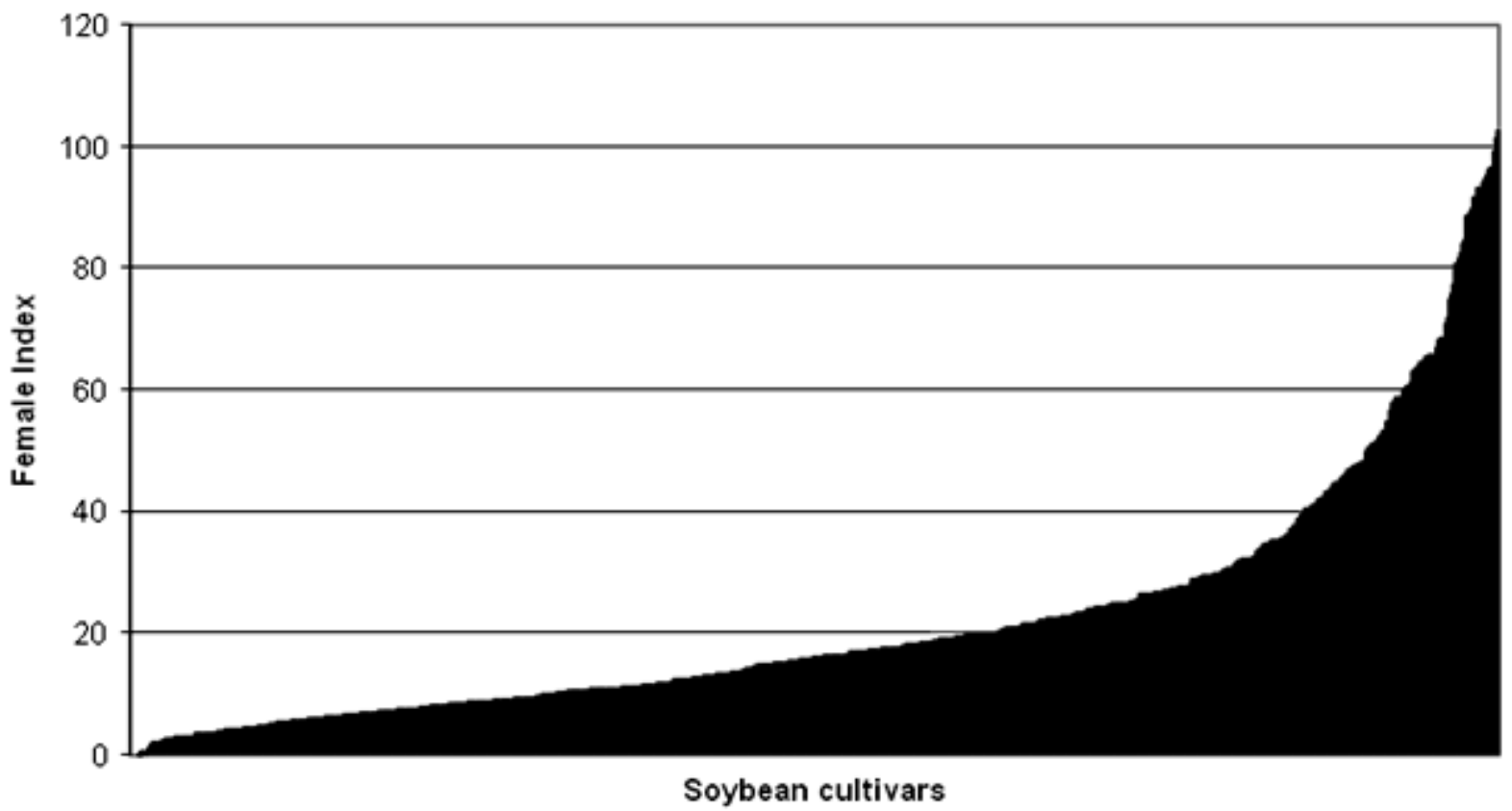

Fig. 2. Female Indices ( FI) of 622 soybean cultivars labeled "race 3 resistant" infested with 1,000 eggs of an HG Type 0 (formerly, "race 3" or "race 6") SCN population after 30 days in a greenhouse in 2007. Cultivar number 1 (the leftmost bar in the graph) is Plant Introduction (PI) 88788, the source of resistance of $96 \%$ of the other 621 cultivars. FI values are calculated from replicated results as follows: (mean number of females on test cultivar) $\div$ (mean number of females on 'Lee 74 ') $\times 100$. Those cultivars with $\mathrm{FI}<10$ are considered resistant.

\section{History of Screening for SCN Resistance}

The identification of SCN resistance in soybean has been quite successful in that resistant breeding lines were identified, from which numerous highly useful cultivars were derived by public and private soybean breeders. Recent reviews of these efforts may be found by Cook and Noel (9) and Shannon et al. (30). The issue at hand is not whether several different methods can be used to successfully identify SCN resistance (which they demonstrably can), but whether the level of resistance can be measured (assessed) reliably so that unbiased cultivar comparisons can be made. 
The first documented screening program for SCN resistance in a breeding program was conducted during the 1950s in SCN-infested fields with a "doublerow" method involving paired rows of susceptible and test lines (28). The large land, labor, and seed investment required for field screening of thousands of soybean breeding lines led others to develop greenhouse protocols. Early greenhouse screening of soybean breeding materials was conducted with infested soil in clay pots (13). Field and greenhouse methods similar to these early ones are still in use in some soybean breeding programs today. The major source of variation in such tests is the variability in SCN population densities in soil. (This variation is not necessarily a negative attribute, especially when simultaneous measurement of yield and/ or genotype by environment interaction is a goal).

The obverse of screening soybean for resistance is identification of SCN virulence profiles, or "races." Methods used in determining virulence profiles of SCN populations were adopted for resistance screening programs beginning with the methods used for the initial description of SCN races by Golden et al. (17). Many programs adopted other methods intended to reduce variation, such as the use of quantified inoculum (cysts or eggs), environmental control, and transplants. The most recent summary of such mostly unpublished refinements was included in the protocol for determining the virulence phenotypes of SCN populations (24). This method later proved to be the most robust among 13 different methods compared for determining levels of SCN resistance in soybean (19) (J. Hicks, unpublished data).

\section{Development of SCE08}

Recognition of the potential negative impact on soybean producers of situations as illustrated in Fig. 2, wherein many cultivars labeled "resistant" do not actually have an effective level of resistance. This led the Production Committee of the United Soybean Board to support a meeting in March 2007 of representatives of public and private soybean breeding and SCN-resistant soybean cultivar assessment programs. The purpose of the meeting, "Assessment of Resistance to the Soybean Cyst Nematode," was to exchange information, decide whether action on SCN resistance assessment issues was necessary and appropriate, and determine whether consensus on measuring resistance could be achieved. One outcome of the meeting was the initial draft of a standardized assessment protocol, described by von Qualen (32). The meeting participants agreed to circulate the protocol, and to present it at the 4 th National SCN Conference in March 2008 for revision and possible adoption. Approximately 75 conference attendees participated in the session devoted to assessment of resistance, and the greenhouse assessment protocol described in the following sections is a result of the consensus achieved in that session.

Use three different SCN populations. Soybean cyst nematode populations can vary in their virulence, even those identified as the same HG Type. After conducting assessments with three different SCN populations of the same HG Type, the characterization of a soybean cultivar will more likely be reproducible and the indicated resistance will likely be effective in a broad range of fields infested with that SCN HG Type. Companies may maintain SCN populations of defined HG Types for testing, or some or all of the testing could be sent to independent laboratories. The SCN populations should be increased for at least five generations on one of the following susceptible cultivars: Lee 74, Hutcheson, Essex, or Williams 82. Increasing the SCN population on a susceptible cultivar will provide ample nematodes for conducting multiple tests with the populations and will help prevent a shift in the frequencies of genes that affect virulence. The use of SCN field populations in greenhouse assessments without increase for several generations is discouraged because field populations may exhibit various levels of dormancy and may be contaminated with parasites and predators, which can contribute to inconsistent results.

Use at least three single plant replications. Assessments of resistance of soybean cultivars conducted with three SCN populations replicated three times will produce nine data points for each cultivar. This minimum amount of replication applies to greenhouse assessment of released cultivars only; earlier generation greenhouse screening for resistance may require more or less replication depending on the specific purpose of the test. 
Use standard methods and environmental conditions. The protocol for conducting HG Type tests described by Niblack et al. (24) should be used for assessing the SCN resistance of soybean cultivars in the greenhouse. The important points are as follows:

- Surface disinfest the seed (e.g., soak seeds in $1 \% \mathrm{NaOCl}$ followed by two or more rinses in sterilized distilled water).

- Germinate seed in sterilized germination paper for three days.

- Transplant seedlings of uniform size and vigor into a pasteurized sandy soil mix. Do not use soilless mixes or soil amendments such as peat moss or vermiculite; they will interfere with extraction and counting of SCN females.

- Use containers with a volume of 100 to $500 \mathrm{~cm}^{3}$.

- Use a randomized complete block or completely randomized experimental design.

- One day after transplanting seedlings, extract eggs and second-stage juveniles (J2) from cysts maintained as described in the previous section. Eggs can be disinfested with sodium hypochlorite or other treatments to improve egg hatch (5).

- Deliver a suspension of eggs and J 2 to containers at the rate of 20 eggs + $\mathrm{J} 2 / \mathrm{cm}^{3}$ soil.

- Maintain soil temperature at $27^{\circ} \mathrm{C}$ to $28^{\circ} \mathrm{C}$.

- Maintain 16-h day length.

- Incubate for 28 to 30 days.

- Dislodge females from roots on nested sieves (20 mesh over 60 mesh = 850- $\mu \mathrm{m}$-pore sieve over 250 - $\mu \mathrm{m}$-pore sieve) with water spray and manipulation.

- Count females under appropriate magnification.

Include HG Type indicator lines. For research purposes, the entire set of HG Type indicator lines should be used. For assessment of resistance among released cultivars, include at least the sources of resistance in the soybean lines being assessed. The seed for the HG Type indicator lines should be procured from the USDA Soybean Germplasm Collection (curator, Dr. R. L. Nelson, USDA-ARS, Department of Crop Sciences, University of Illinois, Urbana 61801; rlnelson@uiuc.edu).

Use more than one susceptible check. The HG Type protocol (24) requires that Lee 74 be used as the susceptible check; however, Lee 74 often fails to germinate well or maintain vigor under SCN pressure (P. R. Arelli, P. A. Donald, T. L. Niblack, G. L. Tylka, and J. Wilcox, unpublished data). Lee 74 need not be used for assessment purposes. We recommend the inclusion of Essex, Hutcheson, or Williams 82 as positive controls. Data confirming the validity of using Essex and Hutcheson are given in the following section. Williams 82 has been observed by several of us to be SCN tolerant and the equivalent of Essex and Hutcheson as a host for SCN (P. A. Donald, G. L. Tylka, and J. Wilcox, unpublished data).

The number of females on the susceptible check must be 100 or more. As for the HG Type test, if the average number of females on the susceptible check is less than 100, the data from that test should not be used. A low average may be caused by problems at several stages in the assessment, all of which invalidate the results. For a comment on variability, please see the section entitled "complementary information."

Calculate the Female Index (FI). The FI value has been the standard for race testing and measuring resistance for over 50 years as of this writing. FI is calculated as follows: [(average number of females per entry) $\div$ (average number of females per plant on the susceptible check)] $\times 100$. Preliminarily, there will be three FI values for each soybean cultivar being assessed (one per SCN population). The final reported FI value for each cultivar should be the average for the three SCN populations. 
Label the cultivar according to FI value. Soybean cultivars should be labeled as to their level of resistance according to the scale proposed by Schmitt \& Shannon (29) (Table 1). Adherence to the standards described herein should be included on the seed bag label, along with the HG Type of the SCN populations used in assessing the cultivar must be included. For example:

- "Resistant to SCN HG Type 0, according to SCE08 standard protocol."

- "Moderately Resistant to SCN HG Type 2.5.7, according to SCE08 standard protocol."

- "Moderately Susceptible to SCN HG Type 2, according to SCE08 standard protocol."

Table 1 . Thresholds for labeling soybean cultivar level of resistance to the soybean cyst nematode [adapted from Schmitt and Shannon 1992 (29)].

\begin{tabular}{|l|l|l|}
\hline Female Index* & Rating & Label \\
\hline$<10$ & Resistant & R \\
\hline 10 to $<30$ & Moderately resistant & MR \\
\hline 30 to $<60$ & Moderately susceptible & MS \\
\hline 60 or higher & Susceptible & S \\
\hline
\end{tabular}

* Female Index values are calculated from replicated results as follows: (mean number of females on test cultivar) $\div$ (mean number of females on 'Lee 74 ') $\times 100$. Those cultivars with FI $<10$ are considered resistant.

\section{Field Evaluations of SCN Resistance}

The main advantage to greenhouse evaluation of resistance according to a standard protocol is, of course, that farmers can use the information to make direct comparisons of cultivars. When standards are lacking, direct comparisons of products are not possible and misleading or misunderstood labeling is common.

The main limitation of greenhouse evaluation is that it can tell us little about performance of soybean cultivars in the field. An enormous body of research shows that SCN-resistant cultivars usually yield more than susceptible ones in SCN-infested fields, but a large and growing body shows that yield is dependent on many other factors than just SCN population density, even without considering the obvious non-SCN factors (soil type, fertility, moisture, and so forth). SCN population densities can vary from zero to tens of thousands of eggs and juveniles per cubic centimeter of soil in a single field $(2,12,16)$, and because yield is affected by SCN population density, the overall impact of SCN on yield will vary from plot to plot and from field to field. In addition, the distribution of virulence phenotypes of SCN can vary within a field, so that a given cultivar may behave as a "resistant" in one area of a field while simultaneously behaving as a "susceptible" in a different area. (The level of resistance of the cultivar does not change; the relative frequency of SCN individuals that can overcome the resistance may change from one part of a field to another). For these reasons, in a recent review of SCN resistance screening, Shannon et al. (30) emphasized that evaluation in the field is necessary to verify cultivar performance. There is no substitute for widespread field evaluations.

Another advantage of field assessment of SCN-resistant cultivars is that it can be used to identify tolerance, which cannot be identified in a greenhouse. For this reason, tolerance has been an underused tool for SCN management. A cultivar is tolerant to SCN if, when infected, it yields well, i.e., similar to its yield if noninfected. Boerma and Hussey (3) suggested that susceptible tolerant cultivars could have an advantage over resistant cultivars because they yield well without exerting selection pressure on the SCN population. There has not been enough research in this area to conclude that the use of tolerance to SCN should be incorporated into management recommendations, but considering its potential usefulness in the face of alarming virulence shifts [e.g., $(15,18,25)]$, more field evaluations should be undertaken with the identification of tolerance in mind. 


\section{Complementary I nformation}

Two items in the preceding section have not received specific research attention and require additional comment: (i) the equivalence of using Lee 74, Essex, Hutcheson, and Williams 82 as susceptible checks; and (ii) checking for unacceptable variability in screening results.

To test for the equivalence of Lee 74 and Essex as susceptible checks, we analyzed data collected for the Illinois Soybean Variety Test program, which has included assessing for SCN resistance since 2001. Up to 700 soybean cultivars labeled as SCN-resistant are checked for resistance to HG Type 0 and HG Type 2- each year at both the University of Illinois and Southern Illinois University. Included in the University of Illinois tests are Lee 74 and Essex as susceptible checks. Data from 14 such tests (i.e., 7 years $\times 2$ SCN populations) analyzed with PROC GLM of SAS 9.1 (SAS Institute Inc., Cary, NC) showed no significant difference $(\mathrm{P}<0.0001)$ between the number of females produced on Lee 74 (148/ plant) and the number produced on Essex (162/plant) when the number of females produced on each was greater than 100.

To test for the equivalence of Hutcheson and Lee 74 as susceptible checks, a separate test was conducted. Both cultivars were infested with 1,500 eggs from each of 34 different SCN populations representing HG Types 0 and 2- from different geographic origins. The SCN populations were maintained in a greenhouse on Essex after being originally collected in Canada (Ontario) or the United States (Arkansas, Illinois, Iowa, Kansas, Louisiana, North Carolina, Minnesota, Missouri, South Dakota, and Tennessee). The tests were initiated and conducted according to the protocol described previously (24) and in previous sections herein. Data analyzed with PROC MIXED of SAS 9.1 showed no significant difference $(\mathrm{P}<0.0001)$ between the number of females produced on Lee 74 (231/ plant) and the number produced on Hutcheson (221/plant) when the number of females produced on each was greater than 100.

Finally, the issue of variability must be addressed. The assessment of soybean cultivars for resistance to SCN is a bioassay, and as such, involves inherent variation. In the SCN-soybean pathosystem, the potential for variation is compounded because both SCN populations and soybean cultivars are measurably variable. SCN varies in virulence within and between populations $(7,23)$; the genetic basis of virulence is still unknown. Resistance to SCN in soybean is determined by several quantitative trait loci (QTL) of which the best known, rhg1 $(8,11)$, has different effects depending on the genetic background (4). There are many ways to deal with variation (the best being to avoid it). In soybean cultivar assessment programs for SCN resistance, variation is arbitrarily limited in several ways. For example, variation among HG Type 0 SCN populations is artificially limited because of the " $10 \%$ rule" established by Golden et al. (17), and variation among soybean cultivars in their host status is removed by imposing qualitative definitions on quantitative data, such as the resistance categories proposed by Schmitt and Shannon (29). Following these arbitrary but arguably useful models, the Illinois Soybean Variety Test program routinely discards data for any soybean cultivar where the coefficient of variation (CV) for FI values is greater than 30\% (T. Niblack, unpublished data). The test is repeated for these cultivars, and if the repeat has a CV $>30$, then resistance is reported as "not determined." The original reason for this practice was that some "cultivars" were actually blends, but it also serves to identify entries for which seed may be mixed or which may still be segregating for resistance.

\section{Conclusions}

Soybean plants are assessed for resistance to SCN for several goals, such as to identify sources of resistance, to verify resistance among soybean lines in development during the breeding process, and to compare released soybean cultivars. Each of these goals may require a different approach. Our concern is for the labeling of commercial SCN-resistant cultivars, i.e., those released for sale to soybean producers. Because there are no existing standards for such labeling, a number of cultivars are marketed as SCN-resistant despite low levels of resistance. And, without independent assessment of soybean cultivars for resistance to SCN, farmers may be misled into using moderately susceptible or 
susceptible cultivars when they intended to use those with resistance or moderate resistance, resulting in lower yield and (or) higher SCN populations. Increases in SCN population densities resulting from farmers unintentionally growing soybean cultivars lacking SCN resistance is particularly undesirable because eggs can survive for more than a decade (20) and population densities decline slowly when nonhost crops are grown $(6,27)$, particularly in the upper Midwest.

Our objective, as nematologists, plant pathologists, and soybean breeders who work on the SCN-soybean pathosystem, is to provide information that leads to both increased yields and lower SCN population densities through use of high-yielding SCN-resistant cultivars. Use of the standards described in this paper by those responsible for cultivar development should allow for direct comparisons among cultivars by soybean producers and improve soybean production in SCN-infested environments.

\section{Acknowledgments}

We thank Mark Halsey, Keith Smith, and David Wright for their invaluable assistance and support of the two meetings that led to the development of this protocol. Principal financial support for both meetings was provided by the United Soybean Board. Additional contributions from the following soybean checkoff sources were greatly appreciated: the North Central Soybean Research Program and the Illinois Soybean Association. The following private sources of support were critical to the accomplishment of the consensus reported herein: Bayer Crop Science, Inc., Monsanto, Inc., Plant Health Care, Inc., and Syngenta Seeds, Inc. Research support for the standard susceptible test was provided by the Illinois Soybean Association and the Missouri Soybean Merchandising Council. We thank S. Y. Chen, E. C. McGawley, G. R. Noel, C. H. Opperman, R. D. Riggs, J. Smolik, T. Todd, J . A. Wrather, and L. D. Young for soybean cyst nematode isolates.

\section{Literature Cited}

1. Anonymous. 2007. Varietal Information Program for Soybeans. Illinois Soybean Association, Bloomington, IL.

2. Avendano, F., Pierce, F. J., and Melakeberhan, H. 2004. Spatial analysis of soybean yield in relation to soil texture, soil fertility and soybean cyst nematode. Nematology 6:527-545.

3. Boerma, H. R., and Hussey, R. S. 1984. Tolerance to Heterodera glycines in soybean. J. Nematol. 16:289-296.

4. Brucker, E., Carlson, S., Wright, S., Niblack, T., and Diers, B. 2005. Rhg1 alleles from soybean PI 437654 and PI 88788 respond differentially to isolates of Heterodera glycines in the greenhouse. Theor. Appl. Genet. 111:44-49.

5. Charlson, D. V., and Tylka, G. L. 2003. Heterodera glycines cyst components and surface disinfestants affect H. glycines hatching. J. Nematol. 35:458-464.

6. Chen, S. Y., Porter, P. M., Reese, C. D., and Stienstra, W. C. 2001. Crop sequence effects on soybean cyst nematode and soybean and corn yields. Crop Sci. 41:18431849.

7. Colgrove, A. L., Smith, G. S., Wrather, J . A., Heinz, R. D., and Niblack, T. L. 2002. Lack of predictable race shift in Heterodera glycines - infested fields. Plant Dis. 86:1101-1108.

8. Concibido, V. C., Diers, B. W., and Arelli, P. R. 2004. A decade of QTL mapping for cyst nematode resistance in soybean. Crop Sci. 44:1121-1131.

9. Cook, R., and Noel, G. R. 2001. Cyst nematodes: Globodera and Heterodera species. Pages 71-108 in: Plant Resistance to Parasitic Nematodes. J . L. Starr, R. Cook, and J. Bridge, eds. CABI Publ., New York, NY.

10. Creech, J. E., J ohnson, W. G., Faghihi, J ., and Ferris, V. R. 2007. Survey of Indiana producers and crop advisors: A perspective on winter annual weeds and soybean cyst nematode (Heterodera glycines). Weed Technol. 21:532-536.

11. Diers, B. W. 2008. Studies on the effects of major SCN resistance genes. Pages 2123 in: Proceedings of the 4th National SCN Conference. T. L. Niblack, ed. Univ. of Illinois, Urbana, IL.

12. Donald, P. A., Donald, W. W., Keaster, A. J ., Kremer, R. J ., Kendig, J . A., Sims, B. S., Mihail, J. D. 1999. Changes in Heterodera glycines egg population density in continuous Glycine max over four years. J . Nematol. 31:45-53. 
13. Epps, J . M., and Hartwig, E. E. 1972. Reaction of soybean varieties and strains to soybean cyst nematode. (Abstr.) J . Nematol. 4:222.

14. Faghihi, J ., and Ferris, V. R. 2006. Soybean Cyst Nematode. Coop. Ext. Serv. Pub. no. E-210-W. Purdue Univ., West Lafayette, IN.

15. Faghihi, J ., Ferris, V., Donald, P., Noel, G., and Welacky, T. 2008. Changes in resistance of PI88788 to field populations of soybean cyst nematode (SCN). Proc. of the 4th Nat'l. Soybean Cyst Nematode Conf., Tampa FL, March 6-7, 2008.

16. Gavassoni, W. L., Tylka, G. L., and Munkvold, G. P. 2001. Relationships between tillage and spatial patterns of Heterodera glycines. Phytopathology 91:534-545.

17. Golden, A. M., Epps, J . M., Riggs, R. D., Duclos, L. A., Fox, J . A., and Bernard, R. L. 1970. Terminology and identity of infraspecific forms of the soybean cyst nematode, Heterodera glycines. Plant Dis. Reporter 54:544-546.

18. Hershman, D. E., Heinz, R. D., and Kennedy, B. S.2008. Soybean cyst nematode, Heterodera glycines, populations adapting to resistant soybean cultivars in Kentucky. Plant Dis. 92:1475-1476.

19. Hicks, J . 2008. Evaluating phenotypic SCN screening methods. Pages 44-45 in: Proc. of the 4th Nat'l. SCN Conf. T. L. Niblack, ed. Univ. of Illinois, Urbana, IL.

20. Inagaki, H., and Tsutsumi, M. 1971. Survival of the soybean cyst nematode, Heterodera glycines Ichinohe (Tylenchida: Heteroderidae) under certain storing conditions. Appl. Entomol. Zool. 6:156-162.

21. Koenning, S. R., 2004. Resistance of soybean cultivars to field populations of Heterodera glycines in North Carolina. Plant Dis. 88:942-950.

22. Minor, H. C., Morris, C. G., Mason, H. L., Knerr, D. R., Hasty, R. W., Stafford, G. K., and Fritts, T. G. 1999. Soybean: 1999 Missouri Crop Performance. Spec. Rep. 527. Missouri Ag. Exp. Station, Coll. of Ag., Food and Natural Res., Columbia, MO.

23. Niblack, T. L. 2005. Soybean cyst management reconsidered. Plants Dis. 89:10201026.

24. Niblack, T. L., Arelli, P. R., Noel, G. R., Opperman, C. H., Orf, J . H., Schmitt, D. P., Shannon, J . G., and Tylka, G. L. 2002. A revised classification scheme for genetically diverse populations of Heterodera glycines. J . Nematol. 34:279-288.

25. Niblack, T. L., Colgrove, A. L., Colgrove, K., and Bond, J . P. 2008. Shift in virulence of soybean cyst nematode is associated with use of resistance from PI 88788. Online. Plant Health Progress doi:10.1094/ PHP-2008-0118-01-RS.

26. Niblack, T. L., and Tylka, G. L., eds. 2008. Soybean Cyst Nematode Management Guide, 5th Edn. N. Central Soybean Res. Prog., Urbandale, IA.

27. Porter, P. M., Chen, S. Y., Reese, C. D., and Klossner, L. D. 2001. Population response of soybean cyst nematode to long term corn-soybean cropping sequences in Minnesota. Agron. J . 93:619-626.

28. Ross, J . P., and Brim, C. A. 1957. Resistance of soybeans to the soybean cyst nematode as determined by a double-row method. Plant Dis. Rep. 41:923-924.

29. Schmitt, D. P., and Shannon, G. 1992. Differentiating soybean cyst nematode race and resistance response of soybean. Crop Sci. 32:275-277.

30. Shannon, J . G., Arelli, P. R., and Young, L. D. 2004. Breeding for resistance and tolerance. Pages 155-180 in: Biology and Management of the Soybean Cyst Nematode. D. P. Schmitt, J . A. Wrather, and R. D. Riggs, eds. Schmitt \&Assoc., Marceline, MO.

31. Tylka, G. L., Gebhart, G. D., and Marett, C. C. 2008. Evaluation of Soybean Varieties Resistant to Soybean Cyst Nematode in Iowa in 2007. IPM 52 Revised J anuary 2008. Iowa State Univ., Ames, IA.

32. Von Qualen, R. 2008. Proposal for a standard method of evaluating soybean varieties for SCN resistance - SCE07. Pages 46-48 in: Proc. of the 4th Nat'l. SCN Conf. T. L. Niblack, ed. Univ. of Illinois, Urbana, IL.

33. Workneh, F., Tylka, G. L., Yang, X. B., Faghihi, J ., and Ferris, J . M. 1999. Regional assessment of soybean brown stem rot, Phytophthora sojae, and Heterodera glycines using area-frame sampling: Prevalence and effects of tillage. Phytopathology 89:204-211.

34. Wrather, J. A. 2008. Impact of SCN on world soybean supply. Pages 1-3 in: Proc. of the 4th Nat'l. SCN Conf. T. L. Niblack, ed. Univ. of Illinois, Urbana, IL. 